\title{
Teachers' and students' views and attitudes towards a new mathematics curriculum: a case study (Note 1)
}

\author{
João Pedro Ponte \\ João Filipe Matos \\ Henrique Manuel Guimãraes \\ Leonor Cunha Leal \\ Ana Paula Canavarro
}

\begin{abstract}
The education system in Portugal is in the midst of a period of intensive reform. This paper describes the findings of a qualitative case study focusing on the views and attitudes of teachers and students participating in a pilot curriculum development programme stressing active methodologies and group work, conducted by the Ministry of Education In particular it discusses their views and attitudes about mathematics, mathematics teaching and curriculum innovation. The teachers were found to struggle with a contradiction: whilst they approved the new orientations, which were seen as adequate and innovative, they complained strongly about the design and implementation of the programme Students had a generally positive attitude towards mathematics, although there were differences among them. The 7th graders were satisfied with their mathematics classes and with the new curriculum. The 10th graders did not consider the changes as significant in themselves, but expressed concern for their academic progress.
\end{abstract}

In many countries, reform in mathematics education is a current major concern. Curriculum theory has moved from discussion about educational and psychological perspectives (Howson, Keitel \& Kilpatrick, 1981; Robitaille \& Dirks, 1982) to considerations about the models and dynamics of curriculum change (Burkhardt, Fraser \& Ridgway, 1986; Popkewitz, 1988) and the politics of curriculum hegemony (Dowling \& Noss, 1990). However, a neglected aspect of the change process is a study of the role, views and attitudes of the most relevant participants: teachers and students. Consequently we felt it important to explore such questions as: What is it like to be in a school involved in such an experience? How do secondary school mathematics teachers participate in the process of curriculum change? How do they perceive the problems raised by that process? How is a new curriculum viewed by teachers and students? How does it affect their teaching and learning experiences?

\section{THEORETICAL BACKGROUND}

The reasons for studying the views and attitudes of teachers is grounded in the assumption that these have a significant influence on their thinking and actions. Views and attitudes act as a sort of filter. They are indispensable in forming and organising the meaning of things, 


\section{TEACHERS AND STUDENTS}

but on the other hand they can block the perception of new realities and of the identification of new problems.

Mathematics teachers organise the learning experiences of their students and consequently are in a critical position to influence their views, conceptions and attitudes. However, we know very little about the relationships between the views of teachers and those of their students, nor about the relationships between teachers' conceptions and their classroom practice. In a period of intense educational reform it is also of interest to explore how curriculum innovation affects the way teachers perceive mathematics and mathematics learning.

In fact, mathematics may be regarded as a dynamic science, with its development associated with many historical vicissitudes and contradictions. However, this view contrasts sharply with popular perspectives which consider it as essentially reduced to computational procedures or axiomatic constructions. For those holding such views, mathematics is a closed body of knowledge, absolutely rigorous, completely cut off from reality, in which nothing new and creative can be done except by geniuses (Ponte, 1988). Summarising the research undertaken in the area of teachers' beliefs and conceptions, Thompson (1992) indicates that, in general, teachers have an absolutist and instrumental view of mathematics, regarding it as an accumulation of facts, rules, procedures and theorems. In a study conducted in Portugal, Guimarães (1988) found that teachers tended to regard mathematics just as a school discipline and did not show a significant enthusiasm for it.

Thompson (1992) commented that many conceptions and beliefs which teachers espouse about teaching seem more related to a set of abstract principles than to an operational pedagogical theory. She also indicated that teachers may be mostly concerned with: (a) mathematical content with an emphasis on computational execution or conceptual understanding; (b) students; or, (c) classroom management and organisation. But, as Feiman-Nemser and Floden (1986) recalled, the weight of these concerns clearly varies with the school levels in which they teach. Popkewitz (1988) stressed the influence of the teachers' social view of the children who come to school and their visions of child development.

Guimarães (1988) indicated that Portuguese teachers tended to view the mathematics classroom as consisting of alternate moments of exposition (for which they are responsible) and practice (to be carried out by the students). In exposition, the information is given by the teacher to the student; the process is a question-answer dialogue, sometimes conceptual but more often basically computational. Practice is constituted by more or less direct exercises and takes up most of the teaching time; the learning situations tend to be highly structured with little problematic content; and the most important interaction is that between teacher and student. 


\section{TEACHERS AND STUDENTS}

In addition, the views, attitudes, and expectations of students regarding the discipline of mathematics have been considered to be a very significant factor underlying their school experience and achievement (Borasi, 1990; Schoenfeld, 1985). Their general conceptions shape the way they approach mathematical tasks, in many cases leading them down non-productive paths. Students have been found to hold a strong procedural and rule-oriented view of mathematics and to assume that mathematical questions should be quickly solvable in just a few steps, the goal being to get the "right answers". For them, the role of the student is to receive mathematical knowledge and to be able to demonstrate it; the role of the teacher is to transmit this knowledge and to ascertain that the students have acquired it (Frank, 1988).

Such views may prevent students from understanding that there are alternative strategies and approaches to many mathematical problems; different ways of defining concepts and even different constructions due to different starting points. In consequence, students may miss significant mathematical experiences, such as exploring situations, formulating questions, conjecturing relationships and testing them. They may approach mathematical tasks with a very narrow frame of mind which discourages them from developing their own personal methods or building confidence to deal with new mathematical ideas. Associated with these conceptions are students' expectations of what is legitimate in a mathematics classroom, which may lead them to react negatively if the teacher tries to introduce some innovative activities (Ponte \& Carreira, 1992).

Despite the interest this topic has recently attracted, little has been investigated about the possibilities of influencing these general views of students. In particular we know little about the effects of new curriculum approaches which are designed to improve students' views and attitudes regarding mathematics. It would be helpful to know how resilient such conceptions and expectations are once formed, and whether they are a simple consequence of the mathematics classroom environment or mostly dependent on external factors.

\section{CONTEXT OF THE STUDY}

In the Portuguese educational system, mathematics is taught as a separate discipline from the 5th grade (Note 2) and is a compulsory subject up to the end of the 9th grade. With the exception of a few students who choose to specialise in the humanities, most continue with mathematics until the end of the 12th grade. The overwhelming majority of schools are public and follow a nationally prescribed curriculum, as too does the private sector which accounts for a very small number of schools.

Mathematics teachers for the 5th and 6th grades, who are also expected to teach science, come from a wide range of academic backgrounds. Those teaching 7th to the 12th grade should hold a degree in mathematics (or possibly engineering) and a practicum, but, 


\section{TEACHERS AND STUDENTS}

due to the shortage of qualified teachers, a considerable number of provisional teachers (Note 3) can be found in middle and secondary schools.

The former Portuguese mathematics curriculum, developed in the 1970s, still contains a strong "new math" flavor. Much emphasis is put on logical terminology, symbolism and abstract algebraic structures. Geometry plays a secondary role and statistics is almost non-existent. Computational skills (first arithmetic and later algebraic) are considered as very important and are taught from the 1 st to the 12 th grade. The Ministry of Education has for a long time defended the merits of this approach and refused to introduce any significant changes.

However, since 1986 a reform of the public educational system has been underway led by the Ministry of Education and is intended to be comprehensive and global. It includes, for example, the creation of new professional schools, the reorganisation of the set of school disciplines, the development of new curricula, the establishment of a new system for school administration and the design of new assessment schemes. Compulsory schooling has been extended from the 6th to 9th grade. Various departments of the Ministry are responsible for planning different aspects of the reform. The drafts of some laws and regulations are frequently submitted to teachers' unions and professional associations, teacher educators, parents' associations and other interested bodies for consultation. Final decisions are always made by the Ministry. In some cases they take account of criticism made; in others they decide to ignore the advice of the majority of respondents. This process may be regarded as a variant of the classical "top down" approach to educational innovation, in which those affected have no significant input (Howson, Keitel \& Kilpatrick, 1981).

As part of this educational reform, a pilot programme with a new mathematics curriculum for 7 th and 10th grades and for a new 10th grade discipline (called quantitative methods) was conducted, in selected schools, during the school year of 1990-91. Teachers had the choice of participating or not; those who took part had a three hour reduction in their weekly teaching load (which is 22 hours for beginning teachers), and they were assisted by a small group of support teachers, especially appointed by the Ministry of Education. Paradoxically, this new curriculum suggests a new phase in Portuguese mathematics education where the need for change is now accepted by the Ministry itself.

\section{PURPOSE AND METHOD}

The study we report on here was commissioned by a department of the Ministry of Education charged with the evaluation of the whole process of reform. (Instituto de Inovação Educational - IIE) It was sought as a case study of a school, showing how the pilot was unfolding, depicting the feelings of the participants, and indicating the major problems associated with the implementation process. With the agreement of IIE, the scope 


\section{TEACHERS AND STUDENTS}

was narrowed down to the disciplines of mathematics and quantitative methods and the focus put on the participants' views and attitudes.

The research team consisted of the authors of the present paper, none of whom had previously been involved with the new curriculum proposals. On the contrary, we were generally critical of what we perceived as the absence of clear guidelines. The school, unknown to us, was frequented mostly by students coming from upper and middle class families; its teaching staff highly concerned with academic performance.

In this case study, the focus of analysis was the development of the process of curriculum change, and within it, in the mathematics subject matter itself. The study had three main phases. The first phase, preparation, included the formulation of research questions, the planning of field work (with the elaboration of interview and observation guides), the outline of the final report, and a first contact with the field. The second phase included the field work and preliminary data analysis. Finally, the third phase consisted mostly of further data analysis and writing the research report. The approach to the field work and the relationship with the informants were influenced by an interpretive conception of educational research, as described in Goetz and LeCompte (1984), Patton (1987), Merriam (1988) and Eisenhart (1988).

A detailed research plan specified the responsibilities of each of the members of the research team, and the approximate completion dates. Many of the suggestions regarding the design of a case study provided by Yin (1989) were taken into consideration.

Data was collected through interviews (which were audio-taped and later transcribed), observations and documentary analysis. Seven mathematics teachers from the 12 piloting the new curriculum were interviewed and 19 students were interviewed in small groups. Also interviewed were the president of the school, two people from the Ministry staff, three authors of the new curriculum and four support teachers. Observations were made of classes (three at 7th and two at 10th grade), of three teachers' regular meetings, and of a teacher training activity conducted by the support teachers. Document analysis was made of the text of the new curriculum, the supporting materials produced both by the Ministry and by the teachers, and the reports of the advisory teachers. Also considered were statistics on school achievement, reports about the socio-economic level of the students and other school documents.

The field work was conducted by groups of paired researchers (with one focusing on 7 th and another on the 10th grade) and amounted to about 130 hours. The research team had the co-operation of three assistants who transcribed about 50 hours of audio-taped material. Data was analysed, cross-checking all the information available regarding the study questions and collectively discussing the emergent main issues. The final report (Ponte et al, 1991), on which this paper is based, underwent a substantial process of drafting and revision. 


\section{TEACHERS AND STUDENTS}

\section{OVERVIEW OF THE CURRICULUM DEVELOPMENT PROGRAMME}

The pilot curriculum development programme had several components: the selection of the participating schools, the elaboration of the new curriculum documents and their transmission to the schools, the core and supplementary classroom teaching, the teachers' classroom preparation, the provision of ongoing support for the schools in the programme and the collection of feedback to revise the proposed curriculum. In this section we briefly describe the main features which provide the essential frame for our later discussion of the participants' views and attitudes.

\section{The New Curriculum and the Preparatory Stages of the Programme}

The new curriculum proposals were written by two teams of two teachers, one for the 7th and another for 10th grade, temporarily assigned to a central department of the Ministry of Education. It is organised in three strands: knowledge, abilities and attitudes/values. The new curriculum suggested a more informal and intuitive approach to mathematical concepts, with emphasis on graphical representation and real life situations. Other features included the introduction of probability and statistics from an earlier level and greater attention to geometry. In terms of teaching approaches, it suggested the use of active methodologies and recommended the use of calculators and group work from grade 5; at grade 7 , it emphasised the role of problem solving. This new curriculum also required the school to organise interdisciplinary activities, to be supported by regular classroom work from all disciplines, up to a certain number of hours (Note 4).

Inservice training sessions for heads and deputy heads of mathematics departments and for the support teachers were organised at a national level by the Ministry of Education, in with the authors of the curriculum proposals participated. These included two weeks on pedagogical, mathematical and mathematics education issues before the beginning of the school year of 1990-91 and one more week during Spring 1991. At a local level, training for participating teachers was in turn organised by the support teachers with the cooperation of the heads and deputy heads of mathematics and was mostly geared to covering new content topics. The participating teachers felt that some of these sessions were more relevant than others, but all agreed that they were too late, as the school year was just about to begin. During the school year, support teachers provided ongoing support to the participating teachers.

The teacher training process was viewed as consisting essentially of sessions where

some experts provided information and guidance - with perhaps some discussion regarding aspects of the new curriculum or more general topics. This view was held both by the Ministry staff and by the teachers in the field. But whereas the teachers especially 


\section{TEACHERS AND STUDENTS}

valued themes with direct classroom application, the Ministry staff felt that "theoretical" issues would also be of interest.

\section{Activities in the School}

The case study school maintained its usual subject planning meetings. These have a long standing tradition of being neither very popular nor very productive. Usually, general schedules and objectives (especially in terms of content coverage) are agreed upon, but most of the time is spent on minor issues if not on personal controversies. However the three hours given for preparation allowed the participant teachers to change their previous pattern of meetings. Those teaching in the same grade began meeting weekly. After a global joint preparation, each teacher had to do his or her own specific planning, which could vary significantly. Some of the teachers used mostly materials designed by themselves, while others used essentially those sent by the Ministry. The classroom work was, as usual, left very much to the responsibility of each individual teacher.

We were curious to know if these smaller meetings would play a very significant role in the pilot programme, by providing a basis for teacher reflection. However, the meetings that we attended indicated that the teachers took little advantage of such opportunity. The climate was pleasant and relaxed but the focus tended to diverge. There was a noticeable difficulty in making these meetings productive and focused on significant issues. It seems that the individualistic tradition and defensive strategies that often characterise the teachers' professional stance (Feiman-Nemser \& Floden, 1986) were strongly prevalent inhibiting more significant and rewarding working interactions. The teachers were not used to team work and did not develop such skills just because the organisational opportunity arose.

\section{Classroom Work}

Without textbooks, the students made wide use of their notebooks. The 7th grade classes were mostly structured around worksheet activities (containing exercises, conceptual questions and problems). They were carried out by the students often in pairs, but sometimes in groups of four, followed by discussions involving the general participation of the class. Students used the calculator naturally, when it was relevant for the task in hand. The 10th grade class tended to flow around the discussion conducted by the teacher. The main conclusions were written on the blackboard and readily copied down by the students to their notebooks. One of the 10th grade teachers often used some classroom activities which had been written prior to the introduction of the new curriculum proposals. In the quantitative methods class there was little discussion. It was essentially based on worksheet activities, most of which were computational requiring the use of the calculator. Students 


\section{TEACHERS AND STUDENTS}

worked in groups of four in a very relaxed atmosphere with the teacher circulating to attend to individual or group requests.

Overall, we witnessed a variety of classroom activities, depending on the grade level and also on the teachers' preferred styles. Even so, some common differences could be seen with traditional mathematics teaching: much more use of the calculator, more attention to relating mathematics to the real world, and, in some cases, more group work and exploratory activities.

\section{Reformulating the Curriculum Proposals}

The department of the Ministry conducting this pilot programme was also responsible for rewriting the curriculum, which would later be used nationwide. To collect feedback for this revision the authors held two meetings with the participating teachers. They also analysed the reports produced by the support teachers and the written questionnaires completed by the participating teachers. In the opinion of the teachers, the meetings were scarce, short and unproductive. As one teacher commented, in most of them most of the time was spent discussing aspects of the curriculum proposals that they found still unclear, rather than reflecting on findings from actual classroom work. Neither the participating nor the support teachers regarded the questionnaires as an appropriate way to report their experiences.

It became quite apparent that some difficulties existed in the relations between the teachers of the school and the authors. In part, this can perhaps be accounted for by a small episode related to some teaching materials produced in the school, that had been given to the Ministry. The teachers felt that when some of these materials were later disseminated, the appropriate credit was not given to the school. Perhaps a reason for this lack of communication was the distance that marked all the relationships between the authors and the Ministry on the one hand and the participating and support teachers on the other.

The final rewriting of the curriculum was completed before the pilot programme was completed. The process of data collection and curriculum revision was carried out informally, relying on the perceptions and the intuitions of the authors. More systematic, diverse and reliable procedures of data collection and the appointment of an independent panel of mathematics educators to act as consultants to evaluate the results might have significantly improved the whole experience.

\section{THE TEACHERS}

We now present the most salient aspects of the views and attitudes held by the teachers about the new curriculum and the design and unfolding of the pilot programme. We also discuss some of their possible roots and implications. 


\section{TEACHERS AND STUDENTS}

\section{Teachers' Comments}

7th Grade Teachers. Three teachers were interviewed (and their classes observed). One of them was quite experienced and the other two were provisional teachers, still finishing their university degree at evening classes. They said they began the experience with "high expectations", believing that the new curriculum would bring significant improvements for mathematics learning. However, they felt overwhelmed with work and not well prepared. They sharply criticised the Ministry, feeling that to make the pilot successful they should have a much smaller teaching load, with perhaps a free day, less teaching hours a week, and no other grades to teach besides those in the programme. They felt that the training provided was late, insufficient, and often not well organised and that their requests for training on topics such as group work and assessment had not been satisfied. They were quite critical of the supporting materials sent by the Ministry, some of which they felt were not appropriate and required a lot of their time preparing them for classroom use. The teachers viewed the new curriculum as "pointing towards a new methodology", with a higher involvement of students, more group work and exploratory activities, but were critical of the inclusion of extra mathematical topics. One of the younger teachers indicated that she "had difficulties in conducting group work". As one of them said, they felt that their students "were enjoying more the discipline of mathematics".

10th Grade Teachers:. The three teachers interviewed were all quite experienced and had worked for many years in the school. One of them had been head of mathematics (elected by her fellow mathematics teachers) for two years. Both she and another teacher said that they began the pilot programme with enthusiasm. However, they were very critical of the development of the programme by the Ministry. They complained about the lack of time provided for preparation and the quality of the supporting materials made by the Ministry, felt that the training received was insufficient, and questioned the limited contact with the authors. They were in general agreement with the new curriculum, identifying the teaching methodologies as the most innovative aspect. However, they criticised the expansion of the curriculum along with many points of detail. These teachers perceived an emphasis on the development of concepts and on the relation of mathematics with reality, which they supported. They felt uneasy with the fact that students had many different brands of calculators, making it "difficult to cope with such a variety".

The head of mathematics mentioned that "in the beginning many promises were made but afterwards the difficulties just started accumulating". She considered some of the training provided by the Ministry to be too theoretical. However, she liked the training given at the beginning of the school year by support teachers. In her view, participating teachers were being very overworked with the effort put into the preparation of lessons. She was also tiring of her role as head of department, feeling "a great responsibility for 


\section{TEACHERS AND STUDENTS}

supporting all the teachers in this school", and commented that she would not accept a further nomination in the forthcoming election. But, in her opinion, her work as a teacher had improved and the students were benefiting from the experience. As she said: "they are enjoying mathematics better".

Finally, the third teacher, who appeared to be quite isolated, defended the viewpoint of the old curriculum. He was overtly critical, not just about the process of implementation but also of the new proposals themselves. In his opinion, some of the new ideas "were just a waste of time" that would be better spent in "significant teaching".

Quantitative Methods Teacher. Since this discipline was only taught to one class in this school, there was only one teacher of quantitative methods - an experienced mathematics teacher with a degree in statistics. She was rather critical of the programme which she considered to be "badly organised". In her opinion, there was "lack of training, lack of bibliography, lack of supporting materials and a lack of methodological guidelines". Given her specialisation in statistics, she felt there was no way she could refuse to teach this new discipline. She began therefore "with negative expectations", feeling that the teachers did not have the necessary conditions to do a satisfactory job in this programme. She questioned the nature, role and allotted time to this new discipline. In her view "this was not mathematics but something else" — perhaps mostly logic and statistics.

\section{Teachers' Contradictory Stance Towards the Pilot Programme}

The new curriculum presented some innovative ideas that were retained sympathetically by most of the teachers. In fact, their interpretation of the new guidelines, first at the training sessions and later in schools, quickly turned out to be in some aspects more "advanced' than the curriculum itself, especially in the 7th grade. For example, the teachers took seriously the scarce references made to group work and the need for student activity adopting them as their basic teaching approach.

Overall, the Ministry staff viewed the pilot programme as a "success". The teachers complained about the organisational aspects but, with few exceptions, they were very much in favor of the new guidelines and supported their implementation at a national level. However, this experience generated many inner tensions between those at the Ministry who lead the process, and have the power to decide and control and those in the field who struggle to implement the proposals. One aspect that may be regarded as critical in preventing major disruption was the existence of the support teachers whose role was to assist the teachers and discuss their doubts and insecurities. They turned out to be important shock-absorbers. From the teachers' perspective, their availability sharply contrasted with the distance of the authors and Ministry staff.

Involvement in the pilot programme put the participating teachers in quite a contradictory situation. They had volunteered to participate and initially even showed 


\section{TEACHERS AND STUDENTS}

enthusiasm. They were pleased to be involved in an innovative process whose general orientation they supported; they were proud to report that their students were showing a positive attitude towards mathematics. However, the way the programme was designed made their role virtually insignificant. No matter how hard-working and creative they were, nobody would notice, even less value their contribution. The important decisions were made at the top, by the Ministry. Even in rewriting the curriculum the teachers' role was quite irrelevant. They could not but become frustrated at this situation.

The teachers solved this contradiction by drawing a sharp line between what they assumed should be their responsibilities and what they assumed should be those of the Ministry. Whilst they were committed to their own decisions, those of the Ministry they did not feel accountable nor responsible for. In this way they protected their own sense of self-respect and dignity. They could criticise the Ministry and at the same time show that they were acting professionally.

It is interesting to note that all those interviewed at the Ministry (authors and staff) were former teachers and it is likely that many of them will return to the classroom in the future. However, during the pilot, they were on the other side of the fence. They felt that things were going well and saw no reason for the teachers' complaints. They thought very much in terms of their function in their new role, which was to produce a new curriculum and to ensure that it was implemented in the schools. This role seems to have provided the basis for their views.

\section{Teachers' Views and Attitudes}

An important line of research on teachers rests on the assumption that what they do in the classroom is fundamentally influenced by their personal views and beliefs, as if these were essentially an individual matter (see Thompson, 1992). Our study challenges that assumption in two ways, by showing the importance of collective processes and by reinforcing the perspective of a more dialectical interplay between beliefs and practices.

The teachers took their involvement in the pilot seriously, openly discussing and confronting the underlying issues. Most of them appeared to have changed several aspects of their attitudes regarding the mathematics curriculum and also some significant aspects of their own educational practices. They expressed sympathy towards the view that in learning mathematics students need time for exploratory work. They experimented with group work activities, frequently used real world examples and allowed students to use calculators. This is in contrast with the traditional views held by mathematics teachers in Portugal. One outcome of the changes in curriculum was the slower pace of progress through the mathematics. However, these changes in classroom practice were mostly the result of social and professional dynamics (inside the school, at training sessions, in professional meetings) and not of individual reflection and solitary decisions. 


\section{TEACHERS AND STUDENTS}

It is difficult to say how much the changes were merely superficial or apparent and how much they concerned deeply-held views. It is possible that behind many of the new perspectives (apparently) adopted by the teachers still lie many of the old conceptions. However, at least at the level of professed views (which has been the focus of the research done so far), in contrast to the formerly prevalent - conservative - attitudes, these teachers were quite positive towards the new proposals.

Quite significantly, the views and attitudes that underwent the most significant changes had to do with issues that were specifically addressed in the training activities and meetings. On the other hand, the views and attitudes that proved to be more resilient were related to some hidden cultural and professional dimensions which had not been addressed on those occasions.

This suggests that significant change may be bought about by external influences

when teachers interact in groups with the potential for strong internal dynamics. The willingness to try new ideas may develop when these become more credible and get official support, but the enthusiasm and conviction can only be based on a practice that is at least moderately successful. This is another reason to suspect that the relationship between conceptions and practice rather than being linear, is more likely of a didactical nature.

\section{Teachers' Knowledge}

In Portugal, secondary school mathematics teachers undergo a substantial preparation in their subject matter before they start teaching. Their pedagogical preparation may vary some follow educational courses, others just a one year of a supervised internship. With variations in emphasis from country to country, these three aspects, content subject matter knowledge, general pedagogy and practical experience, have been for a long time regarded as essential elements of a teacher's education.

In this pilot, some new topics were introduced into the mathematics curriculum and others were to be approached in a rather different way than they had in the past. The concern with subject matter tends to be overwhelming in these situations. As someone from the Ministry staff remarked: "Mathematics teachers mostly value higher level mathematics as a topic for inservice work". However, knowledge of subject matter was not the exclusive concern of the participating teachers. Pedagogical issues, which in the past used to be treated as secondary, or even trivial, were mentioned by the teachers as important topics to be addressed in inservice sessions. Alongside the history of mathematics and geometry, they also felt the need for training in assessment, group work and development of students' attitudes.

All practicing teachers develop some sort of self-supporting practical knowledge that enables them to prepare and conduct their classes (Feiman-Nemser \& Floden, 1986). The teachers that we interviewed and observed did indeed know how to go about their jobs, 


\section{TEACHERS AND STUDENTS}

albeit with a variety of approaches. But they were in need of help when dealing with new objectives and methodologies and to face the realities of their changing classrooms. They regarded as very important the connections between mathematics and reality but had difficulty explaining how these should be introduced and with what purpose. The teachers viewed problem solving in a positive way, but did not have a clear idea of how and when it could be used in the classroom. They were supportive of the use of calculators, but did not know how to maximise their educational possibilities. They regarded group work as important but sometimes had trouble in organising it in a satisfactory way. The teachers supported what they viewed as "advanced methodologies" but felt insecure in applying them in the classroom. Overall they did not have the necessary skills or knowledge to bring the changes about and sometimes they did not even have a clear idea of what the changes required. It would seem that their existing practical knowledge was not a sufficient basis for the implementation of new teaching approaches and they also needed (and perceived the need) of something more.

Shulman (1986) has suggested that besides pedagogy and subject matter knowledge, teachers also need a strong "pedagogical content knowledge". In his view, this consists of ways of representing the ideas of the subject in a form that makes them accessible to the learner. This idea of a blending of mathematical content with pedagogical knowledge (and with knowledge from other fields, as well as that from the practical experience) has indeed been around for some time (see e.g. Wittman, 1984). Such a blending has to draw on different components of current knowledge to produce a restructuring of the teachers craft knowledge. We might call this pedagogical content knowledge "mathematical didactics", but it seems to have a much broader scope than just the representation of subject matter. It must include a comprehensive body of images, principles, and rules for action, some general, some more specific (Elbaz, 1983), organised with a clear rationale, bearing on the specific nature of the underlying content and powerful enough to guide the actions of the teacher. This kind of knowledge may be essential to give a definite strength, confidence and effectiveness that characterises the performance of more effective teachers. For example, in mathematics, important ingredients of such didactical knowledge will include the nature of mathematical learning experiences, the relation between mathematics and reality and the role of specific thinking processes.

\section{Teacher Reflection}

Reflection is rightly regarded by many educators as a key characteristic of teachers' high level of professionalism (Court, 1991). Teachers need to learn from their experience and improve on the less successful aspects of their activity. They need to decide upon which innovations to introduce into their existing practices. They should be able to justify their beliefs and decisions, not just to themselves but also to public scrutiny, to other members of 


\section{TEACHERS AND STUDENTS}

the profession, to parents and to the general public (Feiman-Nemser \& Floden, 1986). All of that can only be carried out through reflection. However, reflection is not an easy thing to practice, especially if the working conditions do not provide the appropriate organisational stimulus. In fact, even quite innovative experiences have shown that teachers, who participate through their own initiative in such processes, often do not take reflection as far as might be expected (Olson \& Eaton, 1987).

Pedagogical theories may be useful to help teachers take a new look at educational objectives and classroom practices, but they will be of little value if not related to the teachers' own frameworks grounded in reflection on their actual experience. To successfully carry out reflection as a part of one's normal activity is especially difficult for a teacher working in isolation. In this respect the pilot programme marked a beginning of cooperation, but still had many limitations. The teachers were very much trapped by their individualistic working tradition. Even in the context of experimenting with a new curriculum, they tended to operate with a defensive stance rather than adopting a practice of more open sharing of experiences, ideas and concerns. A major obstacle that they need to overcome is the overwhelming concern with the defense of self-image. This may be achieved through the process of collaborative curriculum development and is the reason why the provision for team work is a common explicit concern of innovative programmes. Some aspects of suitable organisational conditions to promote reflection were provided in this pilot programme. In particular the opportunity for common meeting periods, was available. However, individualistic behavior and defensive strategies still were by far the dominant features. Teachers were reluctant to publicly expose their thoughts, concerns and practices in a very intimate way. This may indicate that such personal aspects of their culture are more difficult to change than the mere conceptual adherence to a new pedagogical orientation.

\section{THE STUDENTS}

We now turn to the views and attitudes of the students concerning mathematics teaching and learning and particularly, how they were affected by this curriculum development exercise.

\section{Students' Comments}

7th Grade Students. In general terms, the 7th grade students were satisfied with their mathematics classes and with the new curriculum. In the beginning, they were quite concerned that no textbooks were used, but they eventually felt happy with this. They 


\section{TEACHERS AND STUDENTS}

criticised the supporting materials (prepared by the Ministry), as they "were not ready when they should have been".

These students found that mathematics classes were different. In their view, there was much more group work, reports, investigations; there was more discussion, less work on the blackboard, more work in their notebooks. They regarded the new curriculum as implying more work and more thinking. For some of them, classes were sharply split into two groups: theoretical classes (mostly based on writing on the blackboard) and practical classes (made up of exercises in notebooks), the second being far more common. The mathematics class was seen as practical and active: "In mathematics we are always doing something . . Mathematics is active. It is a more practical subject". The lack of a textbook "required more attention in class". They felt positive towards using calculators — although some reservations were made by two girls who were afraid of losing their computational skills. They did not use the computer, but their opinions about it were sharply divided: some thought that it would help learning and would welcome it into the classroom, whilst others felt differently.

Students recognised some changes in their assessment. Besides tests, other aspects were now also taken into account: absences, attention, behavior, their notebooks, etc. Some felt that the tests had themselves changed: "a new test with few questions corresponds to an old one with many questions".

10th Grade Students. The 10th grade students felt particularly insecure at the beginning of the school year when they found themselves without textbooks. Some even considered the possibility of changing to another school. At the end of the pilot, they were still insecure, concerned in particular at the effect their involvement in the pilot programme might have on their future success and application to University.

Overall, they felt that their school work was satisfactory. In their view, mathematics was the school subject that had seen fewer changes. It still had its theoretical and practical sides, "mathematics is a practical subject ... [You go through] new contents and then solve exercises ... Mathematics is really about making you think".

They did not like very much the supporting materials prepared by the Ministry since they felt that the exercises were too easy; they preferred the materials prepared by their own teachers. Calculators were used in quantitative methods but were now left at home because they were no longer necessary in mathematics (the computations being quite simple). Some students were in favor of group work but most of them wondered if doing investigation-like activities was appropriate for mathematics or better suited for other subjects, such as Portuguese.

These students were much concerned with their grades. They indicated that in their assessment the tests were the dominant factor, but felt that the weight of class participation and other out-of-class work had increased. They particularly disliked the interdisciplinary activities, and regarded them as a distraction from more important learning activities. 


\section{TEACHERS AND STUDENTS}

\section{Quantitative Methods Students}

These are students of the humanities who in the past would have finished their study of mathematics at the 9th grade. They felt that this new discipline was still mathematics but with a different name (which they did not like since they did not like mathematics). They considered that the subject matter was quite boring — "it is always the same thing" — and they missed the security of the regular textbook. They did not like what they called the "horrible" supporting materials and did not have any particular enthusiasm about the use of calculators. These students also did not like group work. However, they had perceived that the assessment had changed somehow, since the analysis of their notebooks and the results of group work were now also taken into account.

\section{Students' Views and Attitudes}

Involvement in the pilot bought quite significant changes for these students. For the first time in school they did not have textbooks. They were presented with a different sort of mathematical activity which was perceived as requiring more thinking: problem solving, exploratory work, use of the calculator. Furthermore, although that was not necessarily new for all of them, they were required to do much group work and engage in interdisciplinary activities.

The students, except those in quantitative methods, reacted in a positive way to not having a textbook. They took care in organising their notebooks and found them a useful basis for study. The challenge of different mathematical activities was well taken up by them. At 7 th grade they were positive about having problems requiring more effort and thinking, and at 10th grade the students took the initiative of asking the teacher more difficult questions. They were quite positive about the active nature of mathematics lessons and their reactions to group work were also generally favorable.

The most notable exception to this general pattern were the students of quantitative methods, but one must regard them as a very special case. They were very unhappy about having to keep studying mathematics and were negative towards everything related to this experience. There is an interesting parallel between the lack of enthusiasm of the students and that of their teacher. It is difficult to know which one came first, it is possible that in some way they were reinforcing each other.

The major difference in the attitudes between the 7 th and 10th grade students is in respect of the interdisciplinary activities. The students in the 7 th grade were positive and those in the 10th grade were negative. It seems that younger students still have an interest in what the school may offer them, while the older ones appear to be driven mostly by personal or career interests, either immediate or long term. 


\section{TEACHERS AND STUDENTS}

This experience notably shows that teachers have the possibility of influencing the attitudes of the younger students. Seventh grade students can afford to be optimistic and willing to accept some of the values and challenges coming from the teachers. On the contrary, the 10th grade students transmitted clearly an image of independence. Their fundamental concern was with admission to the University and they saw the experience as essentially bringing them extra handicaps.

\section{CONCLUSION}

In Portugal, the former mathematics curriculum was established in the mid seventies, but in the last five years or so, signs of dissatisfaction have been clearly increasing, with alternative proposals put forward and informal experiences carried out by teachers and mathematics educators. This created a fertile ground for global change to be regarded positively by many teachers.

The curriculum development programme initiated by the Ministry of Education had a markedly top-down nature, but even so, seems to have encouraged the more enthusiastic teachers (especially those at 7 th grade) to take some of the intended changes further than planned. This brought about much change in classroom practice. Indeed, this study suggests that under some conditions secondary school mathematics teachers may be willing to change some of their views and practices, which in turn even influences the curriculum itself.

The teachers wanted to have a much greater level of participation in this process. Being given just a minor role and feeling treated with little attention, they did not identify themselves personally with the experience. They were caught in a contradictory position, in sympathy with the new approaches, but strongly critical of the process of implementation. The fact that teachers developed a favorable view towards curriculum changes whose value is recognised internationally is encouraging, but this can quickly disappear if these ideas are not consolidated and put into practice. Also, the difficulty some had in developing fruitful working relationships and more reflective practices cannot be underplayed. The shortcomings of the model adopted for teacher training and the absence of intervention of the mathematics education community in this experience further contributed to all its deficiencies.

This experience also shows that secondary school students may be noticeably affected by such curriculum changes in mathematics. They identified differences in the sort of tasks and activities and found the discipline to be more demanding. However, a change in attitudes towards mathematics was only apparent with the younger students. At 7th grade, they adhered to new ways of working and enjoyed having more challenging mathematics classes, even if that implied more work and greater thinking from them. At 10th grade, the students were also able to adjust to the absence of textbooks and to a new 


\section{TEACHERS AND STUDENTS}

style of work, but dismissing these aspects as relatively unimportant compared to their career aspirations.

In summary, secondary school mathematics teachers appear to be able to accept new guidelines calling for a more active role of the student in the learning process, valuing exploratory activities, stressing a more intuitive view of mathematics and of its relation with reality, and regarding new technology in a positive way. However teachers have much more difficulty in changing culturally rooted aspects of their views, attitudes and practices, such as their defensive behavior and individualistic tradition. The teachers were able to have a significant influence on the 7 th grade students, with whom they developed a close relationship. In contrast, the teachers had only a minimal influence on the 10th grade students, as they seemed to have quite established expectations about mathematics classes. The students in the scientific strand wanted to learn but rejected what they perceived as distracting and inefficient learning activities; those in the humanities strand just wanted to avoid mathematics as soon as possible. The changes that influence the expectations of students and affect their normal routines need to be carefully thought through if they are to be successful.

We still have much to learn about the nature of change in education and the implications on the participants' views and attitudes. Successive "turns" or "movements" (eventually followed by periods of stability) have the potential to capitalise on human passion, bringing about the most creative and innovative changes. However, these processes carry with them many inevitable elements of imbalance, which often are hard to control and may take a long time to correct. What appears as a revolution demanding much effort may turn out to be quite superficial and irrelevant. On the other hand, significant changes may result from long term, but small scale, accumulations, based on careful planning and gradual rationalisation. Of course, this format carries its dangers. It may take so long to implement that what was perceived as a needed change becomes no longer important. Individuals may have difficulty in managing the contradiction of moving at a slower pace than they feel possible and desirable. In this experience affective and social factors seemed to prevail in the dynamics of the change process, but it strongly suggests that mathematics educators should have a more significant role in the process of curriculum change, co-operating in curriculum design and evaluation, developing classroom materials, supporting teacher education. Reform in mathematics education is important enough to deserve to be sustained by our best efforts in theoretical and empirical research.

\footnotetext{
Notes:

1. Part of the work for this paper was made by the first author on his sabbatical leave at the University of Georgia, with a grant from the Fulbright Commission and Fundação Luso-Americana para o Desenvolvimento. The authors thank also Peter Gates who edited a former version of the manuscript.

2. In Portugal, grade five pupils are 10 years old or older.

3. The Ministry of Education contract every year a number of "Provisional teachers", who may have varying academic qualification but do not have a professional diploma.
} 


\section{TEACHERS AND STUDENTS}

4. Topics in the 7th grade curriculum include proportion, similarity of figures, rational numbers, statistics (organisation of data, mean, median and mode), space and plane geometry (polihedra, prisms, pyramids, triangles and quadrilaterals — areas and volumes), and 1st degree equations. The 10th grade curriculum contains basic notions of statistics (presentation of data, measures of central tendency and dispersion), real numbers, notions of logic, axioms of Euclidean space geometry, functions (quadratic, absolute value) and Cartesian geometry (vector approach). Quantitative methods includes statistics (presentation of data, measures of central tendency and dispersion, bidimentional distributions), logic (basic connectives, quantifiers, De Morgan laws), real and complex numbers, probabilities (frequentist notion), functions and sequences.

\section{REFERENCES}

Borasi, R.: 1990, 'The invisible hand operating on mathematics instruction: Students' conceptions and expectations'. In Cooney, T. J. (ed.), Teaching and learning mathematics in the 1990s (NCTM Yearbook), NCTM, Reston.

Burkhardt, H., R. Fraser, and J. Ridgway: 1986, The dynamics of curriculum change. A Position Paper for the Mathematical Sciences Education Board Curriculum Frameworks Committee, Shell Centre for Mathematical Education, University of Nottingham.

Court, D.: 1991, 'Studying teachers' values', The Clearing House 64, 389-392.

Dowling, P. and R. Noss (eds): 1990, Mathematics Versus the National Curriculum. Falmer, Basingstoke.

Eisenhart, M.: 1988, 'The ethnographic research tradition and mathematics education research'. Journal for Research in Mathematics Education 19, 99-114.

Elbaz, F.: 1983, Teacher thinking: A study of practical knowledge, Croom Helm, London.

Feiman-Nemser, S. and R. E. Floden: 1986, 'The cultures of teaching'. In Wittrock, M. C. (ed.), Handbook of research on teaching, (3rd ed.), Macmillan, New York.

Frank, M.: 1988, 'Problem solving and mathematical beliefs'. Arithmetic Teacher 35 (1), 32-34.

Goetz, J. P. and M. LeCompte: 1984, Ethnography and qualitative design in educational research, Academic Press, San Diego.

Guimãraes, H. M.: 1988, Ensinar matemática: Concepções e práticas (Master's thesis, Lisbon University). APM, Lisboa.

Howson, G., C. Keitel, and J. Kilpatrick: 1981, Curriculum development in mathematics, Cambridge University Press, Cambridge.

Merriam, S.: 1988, Case study research in education, Jossey-Bass, San Francisco.

Olson, J. K. and S. Eaton: 1987, 'Curriculum change and the classroom order'. In Calderhead, J. (ed.), Exploring teachers' thinking. Cassell Educational, London. 


\section{TEACHERS AND STUDENTS}

Patton, M. Q.: 1987, Qualitative evaluation methods, Sage, Newbury Park.

Ponte, J. P.: 1988, 'Matemática, insucesso e mudança: Problema possível, impossível ou indeterminado?' Aprender 6, 10-19.

Ponte, J. P. and S. Carreira: 1992, 'Spreadsheet and Investigative Activities: a Case Study of an Innovative Experience'. In J. P. Ponte, J. F. Matos, J. M. Matos, and D. Fernandes (eds.), New Information Technologies and Mathematical Problem Solving: Research in Contexts of Practice. Springer, Berlin.

Ponte, J. P., J. F. Matos, H. M. Guimãraes, L. C. Leal, and A. P. Canavarro: 1991, $\underline{\text { O }}$ processo de experimentação dos novos programas de Matemática: Um estudo de caso, Instituto de Inovação Educacional, Lisboa.

Popkewitz, T. S.: 1988, 'Institutional issues in the study of school mathematics: Curriculum research', Educational Studies in Mathematics 19, 221-249.

Robitaille, D. and M. Dirks: 1982, 'Models for the mathematics curriculum'. For the Learning of Mathematics, 2(3), 3-21.

Schoenfeld, A.: 1985, Mathematical problem solving. Academic Press, Orlando.

Shulman, L. S.: 1986, 'Those who understand: Knowledge growth in teaching', Educational Researcher 15(2), 4-14.

Thompson, A. G.: 1992, 'Teachers' beliefs and conceptions: A synthesis of the research'. In D. A. Grouws (ed.), Handbook on research on mathematics learning and teaching, Macmillan, New York.

Yin, R.: 1989, Case study research: Design and methods, Sage, Newbury Park.

Wittman, E.: 1984, 'Teaching units as the integrating core of mathematics education', Educational Studies in Mathematics 15, 25-36.

Department of Education

Faculty of Sciences

University of Lisbon

Portugal 